\title{
Removal of Congo Red and Methyl Red using Low Density Polyethylene- Chitosan Nanoparticles Biocomposite in Single and Binary-component System
}

\section{Oluwatosin Emmanuel Daramola and Oluwaseun Adekoya Adelaja}

Department of Chemistry, School of Sciences, Federal University of Technology Akure, P.M.B. 704, Akure, Nigeria

\begin{abstract}
The low density polyethylene-chitosan nanoparticles (LDPE/CHNP) biocomposite was applied as a biosorbent for the adsorption of Congo red (CR) anionic dye and methyl red (MR) a cationic dye an in single and binary system. The effect of parameter $\mathrm{pH}$, contact time, initial concentration, adsorbent dosage and temperature were studied on the two dyes in single and the binary component system. Kinetic studies showed that adsorption on LDPE/CHNP in a single and binary-component system follows pseudo-second order kinetics. The $R^{2}$ values of CR in single and binary system were gotten to be 0.9996 and 0.9984 respectively, while the $R^{2}$ values of MR in single and binary system were 0.9994 and 0.9983 respectively. The adsorption equilibrium study was tested with both Langmuir and Freundlich isotherm and the result showed they agree more with Langmuir have an $R^{2}$ values for CR in single and binary system to be 0.9995 and 0.9991 respectively, while the $R^{2}$ values of MR in single and binary system were 0.9954 and 0.9983 respectively; which implies that the adsorptions were more of chemisorption than physiosorption reaction. In the single and binary systems, the result reveals that CR had higher adoption efficiency than MR which could be because the chelation between cations and chitosan chains, which decreased the electrostatic interaction between Methyl red and chitosan nanoparticles of the biocomposite. The LDPE/CHNP biocomposite has proved to be an efficient adsorbent for CR (anionic dye) and MR (cationic dye) in single and two-component system which are frequently encountered composition of industrial effluents.
\end{abstract}

Received: January 8, 2021; Accepted: February 25, 2021

Keywords and phrases: adsorption, biosorption, binary-component system, chitosan nanoparticles, Congo red, Methyl red.

Copyright (C) 2021 Oluwatosin Emmanuel Daramola and Oluwaseun Adekoya Adelaja. This is an open access article distributed under the Creative Commons Attribution License, which permits unrestricted use, distribution, and reproduction in any medium, provided the original work is properly cited. 


\section{Introduction}

Wastewater from dye and textile, as well as pulp and paper industries usually contain dye stuff, soluble substances and suspended solids (Yeşim and Başak [1]). Dyes are important pollutants, which results in serious environmental and health hazard to humans, animals and aquatic life. Pigments and dyes transferred into the wastewater system results in contamination of water body which are always difficult to treat. Even after the conventional process of contaminant removal, the colour of the dyes still persist. Several techniques and methods can be employed to achieve the removal of dye from wastewater, such as membrane separation, flocculation, ion exchange, precipitation, adsorption. The conventional method of dye removal is associated with the problem low efficiency and high cost (Zhang et al. [2]). Adsorption or biosorption employing the use of low cost adsorbent or biosorbent is regarded as the simplest, cost-effective and efficient technique (Gupta et al. [3]).

Recently, attention has been drawn towards several biosorbents like bacterial or fungi biomass as well as biopolymers which can be gotten from microorganism in large quantities and they are harmless to nature (Gupta and Suhas [4]; Michalak et al. [5]). The use of chitinous products in the treatment of wastewater has gained considerable attention of recent (Srinivasan and Viraraghavan [6]).

Chitosan is a polysaccharide made up of polymers of glucosamine and $\mathrm{N}$-acetyl glucosamine. It is produced by the partial deacetylation of chitin. Chitin and chitosan have been of commercial interest due to their high nitrogen content, biocompatibility, biodegradability, bio-adhesivity, hydrophilicity, polyfunctionality, adsorption properties and film-forming ability. The cationic nature of chitosan is responsible for most of its properties of chitosan (Wang and Zhuang [7]). The surface charges are responsible for adsorption of the anionic dyes onto chitosan beads and this depends on the solution $\mathrm{pH}$. Dye adsorption onto chitosan or its composites happened by electrostatic attraction on the protonated amine groups present.

The production of chitosan derivatives for the treatment of wastewater containing metal ions has been investigated by various researchers in recent years (Wong et al. [8], Kyzas and Bikiaris [9]). Among these chitosan derivatives, carboxymethyl chitosan is an amphoteric ether derivative containing active carboxyl $(-\mathrm{COOH})$, hydroxyl $(-\mathrm{OH})$, and amino (-NH2) groups in a molecule (Zhang et al. [2]). Removal of Congo red (CR) and Methyl red (MR) from aqueous solutions has been investigated in batch system. The degree of adsorbent affinity for the adsorbate determines its distribution between the solid 
and liquid phases. Various adsorbents had been employed already for removal of these dyes like mango peel, banana peel, coconut bunch waste, wheat husk, tree bark, orange peel, chitosan etc.

Till now, researches on using chitin-chitosan or chitosan composite as an adsorbent has been focused on the single systems. However, relatively less work has been done on exploring the adsorption behavior of cationic and anionic dye in binary systems, which are frequently encountered composition of industrial effluents.

In this study, CR and MR adsorption in single and binary system onto polyethylenechitosan nanoparticles (LDPE/CHNP) biocomposite was tested with two isotherm models, (Langmuir and Freundlich) to describe the equilibrium adsorption. In addition to equilibrium studies, the kinetics of the sorption were determined so as to determine the time course of the dye uptake, this is to provide deep understanding of the pathways and mechanism of reaction of the sorption reactions. Two sorption kinetic models were tested in this study: Pseudo-first order rate equation of Lagergren and the pseudo-second order kinetic rate equation.

\section{Material and Methods}

\subsection{Materials and stock preparation}

LDPE/CHNP prepared from chitosan nanoparticles gotten from blue cab shells was used and LDPE purchased from used Sigma-Aldrich. All chemicals used for this study were of analytical grade gotten from Sigma-Aldrich. Analytical quality deionised water (resistivity 18.2 $\mathrm{M} \Omega \mathrm{cm}$, Millipore) was used throughout to prepare solutions. Congo red (CR) and methyl red (MR) dye solutions of $1000 \mathrm{ppm}$ were prepared by dissolving $1 \mathrm{~g}$ of dyes in $1000 \mathrm{~mL}$ of distilled water. For the binary system $1000 \mathrm{ppm}$ of the solution was prepared by dissolving $0.5 \mathrm{~g}$ each of $\mathrm{CR}$ and $\mathrm{MR}$ in $1000 \mathrm{~mL}$ of distilled water.

\subsection{Biosorption experiments}

The effect of $\mathrm{pH}$, contact time, initial concentration, adsorbent dosage and temperature on the two dyes and the binary mixtures were done using the CHNP15 for the study. A range of $\mathrm{pH} 2-9$ for the $\mathrm{pH}$ study using $0.1 \mathrm{M}$ hydrochloric acid $(\mathrm{HCl})$ and $0.1 \mathrm{M}$ sodium hydroxide $(\mathrm{NaOH})$ to adjust the $\mathrm{pH}$ in a dropwise manner. A period of 30 , $60,90,120$ and 150 minutes was used to investigate the effect of contact time while the effect of initial concentration was done by varying the concentration of the solution from 20, 50, 80, 120 to $150 \mathrm{ppm}$. Effect of adsorbent dosage was studied by varying the mass 
of adsorbent from $0.1 \mathrm{~g}, 0.2 \mathrm{~g}, 0.3 \mathrm{~g}, 0.4 \mathrm{~g}$, to $0.5 \mathrm{~g}$ and effect of temperature on the adsorption process was also investigated from $25,30,35,40$, to $45^{\circ} \mathrm{C}$ and was used to determine the thermodynamic properties of the adsorption process. Agitation speed of 100rpm was maintain throughout the experiment for each study after which the solutions were filtered with $0.1 \mathrm{~mm}$ filter paper and refrigerated. The samples were then taken for analysis.

\subsection{Batch equilibrium and kinetic studies}

In order to carry out the batch equilibrium and kinetics study the concentration of optimum adsorption of CR, MR, CRB, and MRB (60, 70, 60, 100 ppm) respectively were used, with adsorbent dosage of $1 \mathrm{~g}$, at constant $\mathrm{pH}$ while the agitation time were varied from $(15,30,60,90$, and $120 \mathrm{mins})$. The agitation speed of $100 \mathrm{rpm}$ was maintain throughout the experiment for each study after which the solutions were filtered with 0.1 $\mathrm{mm}$ filter paper and refrigerated. The samples were then taken for analysis.

\subsubsection{Equilibrium studies}

Langmuir and Freundlich isotherms were used for the equilibrium study for the purpose of this study (Langmuir [10], Freundlich [11]).

The linearised Langmuir equation is expressed as follows:

$$
\frac{C_{e}}{q_{e}}=\frac{1}{Q_{0} b}+\frac{C_{e}}{Q_{0}}
$$

where $q_{e}$ (in milligrams per gram) is the maximum amount of dye adsorbed at equilibrium, $Q_{0}$ (in milligrams per gram) signifies the dye monolayer capacity of the adsorbent, $b$ (in litres per milligram) is a constant related to energy of adsorption and $C_{e}$ (in milligrams per litre) is the equilibrium dye. If the adsorption system obeys a Langmuir adsorption model, then a plot of $\frac{C_{e}}{q_{e}}$ against $C_{e}$ would give a straight line and the constants $Q_{0}$ and $b$ could be evaluated.

The linearised Freundlich adsorption isotherm is represented by the following equation:

$$
\ln q_{e}=\ln k_{F}+\frac{1}{n} \ln C_{e}
$$

where $k_{F}$ (in milligram per gram) (milligrams per litre) is a Freundlich constant characteristic of a particular adsorption isotherm and $n$ (dimensionless) is a Freundlich constant representing the adsorption intensity. 
If the adsorption system obeys the Freundlich model, then a plot of $\ln q_{e}$ versus $\ln C_{e}$ would give a straight line and constants $k_{F}$ and $n$ could be evaluated.

\subsubsection{Kinetic studies}

In this present work, Pseudo-first-order and Pseudo-second-order model were used to describe the experimental data for the determination of rate constants (Ho and McKay [12]).

The linearised pseudo-first-order equation can be represented by the following equation

$$
\ln \left(q_{e}-q_{t}\right)=\ln q_{e}-k_{1} t
$$

where $k_{1}$ (in minute) is the pseudo-first-order adsorption rate constant and $q_{e}$ and $q_{t}$ are the values of the mass adsorbed per unit mass of adsorbent at equilibrium (capacity) and at time $t$, respectively. Plot of $\ln \left(q_{e}-q_{t}\right)$ versus $t$ for an adsorbent would give a straight line if the adsorption process follows a pseudo-first order kinetic behaviour.

The linearised Lagergren second-order kinetic equation may be represented by the following equation (Ho and McKay [12]):

$$
\frac{1}{t}=\frac{1}{k_{2} q_{e}^{2}}+\frac{1}{q_{e}} \times t
$$

where $k_{2}$ (in grams per milligram per minute) is the pseudo second-order rate constant. Plot of $1 / t$ versus $t$ for an adsorbent would yield a straight line if the adsorption process follows a pseudo-second order kinetic behaviour.

\subsection{Sample analysis}

\subsubsection{Determination of dye concentration}

The amount of dye adsorbed onto the biosorbent was analysed with the use of UVvisible spectrometer $200-600 \mathrm{~nm}$ in a spectrophotometer $(752 \mathrm{~N})$ using a quartz cuvette with distilled water as the reference (Megha et al. [13]). Then the wavelength of $432 \mathrm{~nm}$ and $453 \mathrm{~nm}$ were used for CR and MR in single and binary system respectively and the absorbance were determined. A prepared calibration curve of was then used to determine the various dye concentrations.

\section{Results and Discussion}

\subsection{Characterization of the biosorbent}

The SEM of LDPE/CHNP biocomposite (Figure 1) indicated the LDPE/CHNP 
biocomposite with porous structures. These structural properties might improve the uptake of the Methyl red and Congo red dyes from aqueous solution. Bolanle et al. [14] in their research on adsorption and desorption studies of Delonix regia pods and leaves removal and recovery of $\mathrm{Ni}(\mathrm{II})$ and $\mathrm{Cu}$ (II) ions from aqueous solution had similar observation on the SEM micrograph of the leaves which also suggested them to be a good adsorbent. The result of the micrograph image of LDPE/CHNP suggest that it has the capacity to adsorb dye due to the presence of chitosan nanoparticles in the matrix of LDPE which naturally would not be an adsorbent as the pore sized will be too tight to adsorb.

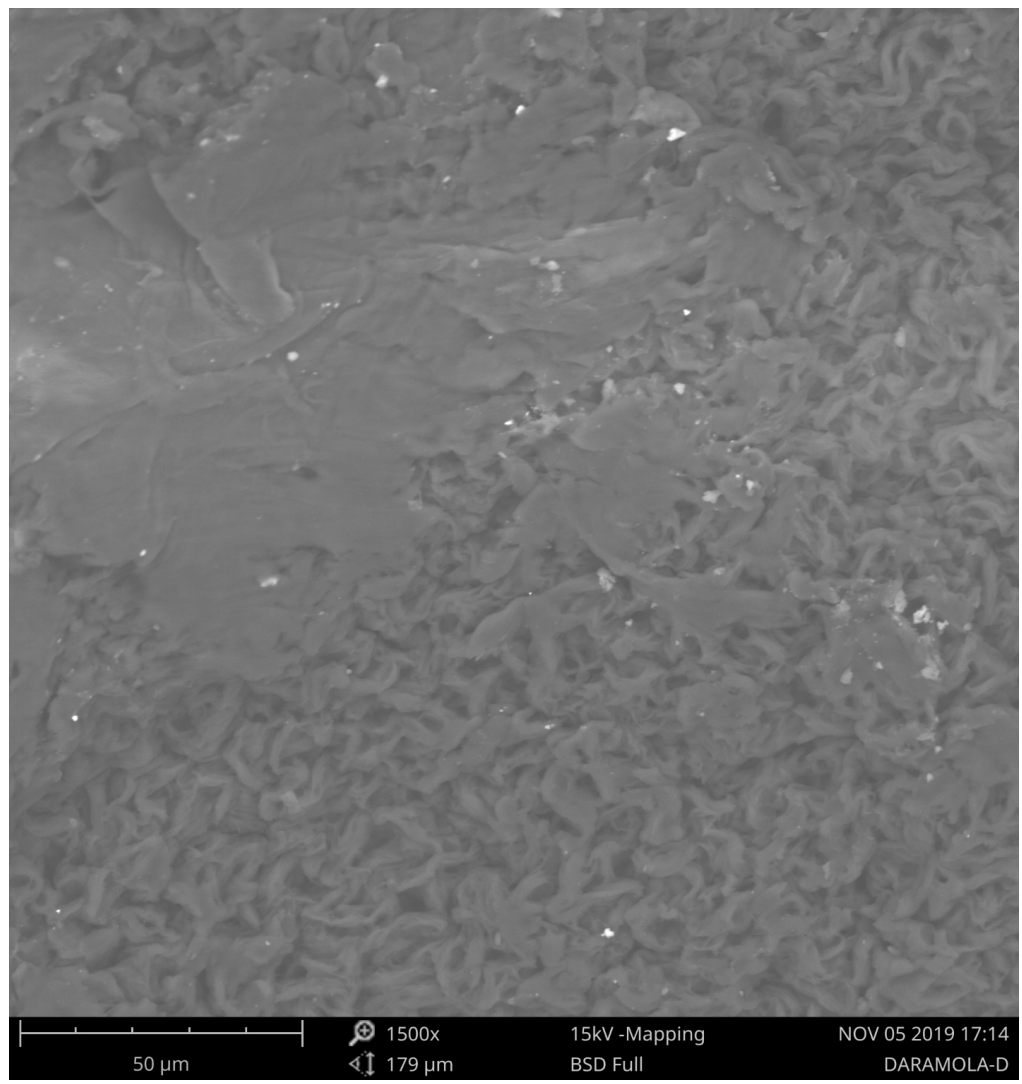

Figure 1. SEM micrograph of the adsorbent (LDPE/CHNP).

FTIR spectra of LDPE/CHNP films in the wave number range of $4000-350 \mathrm{~cm}^{-1}$ are given in (Figure 2). The absorption peaks of chitosan at $3464-3459 \mathrm{~cm}^{-1}$ for amino groups and $\mathrm{OH}$ as well as inter and intra molecular hydrogen bonding is seen in the spectrum of the LDPE/CHNP (Saraswathy et al. [15]). Peaks around in the spectra of 
1107 and $1390 \mathrm{~cm}^{-1}$ seen are due to saccharide structure. Peaks around in the spectra of $1107 \mathrm{~cm}^{-1}$ corresponds to the vibration of COC groups in chitosan since chitosan also belongs to the aliphatic ethers. The peak around $1643 \mathrm{~cm}^{-1}$ and $1551 \mathrm{~cm}^{-1}$ are due carbonyl groups and represent acetylated amino group of chitin, which indicates incomplete deacetylation of the sample (Sunilkumar et al. [16]). The presence of $\mathrm{NH}_{3}$ and $\mathrm{OH}$ group in the biocomposite is a good sign that it should be a good dye adsorbent.

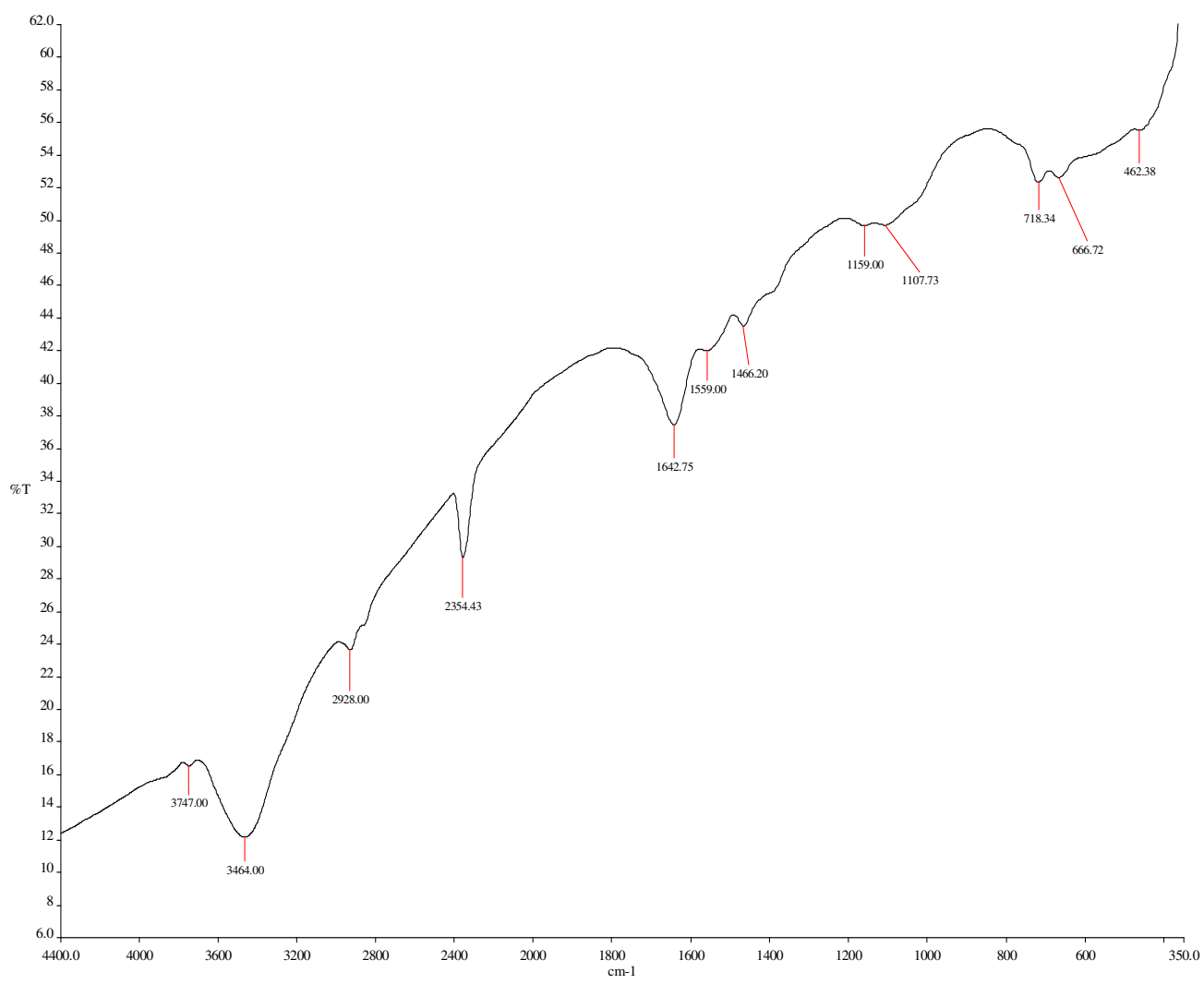

Figure 2. FTIR of the adsorbent (LDPE/CHNP).

\section{2. pH influence on adsorption of Congo red, Methyl red and their binary system}

$\mathrm{pH}$ is an important influencing factor for dye biosorption. Adsorbent surface charge depends on $\mathrm{pH}$ and the structure of the adsorbates species in some instance also depends on the solution $\mathrm{pH}$. In this study, the effects of initial $\mathrm{pH}$ on adsorption of the dyes were investigated over a range of $\mathrm{pH}$ values from 2 to 9 for both single and binary system. As shown in Figure 3, from the $\mathrm{pH}$ of 2 to 3 for the MR, the percentage dye removal dropped 
and was minimum at $\mathrm{pH}$ of 3 and the dye adsorbed increased progressively from the $\mathrm{pH}$ of 3 to 9 where $54 \%$ of the dye was adsorbed. For CR, the minimum adsorption of the dye by the adsorbent was observed at $\mathrm{pH}$ of 2 , which then increased progressively as the $\mathrm{pH}$ increased till $\mathrm{pH} \mathrm{7}$, and from $\mathrm{pH} 7$ to 9 it dropped from $69 \%$ to $65 \%$. The binary system also followed similar trend as the $\mathrm{pH}$ increased the rate of adsorption also increased from $\mathrm{pH} 2$ to 9 , it was also observed that the amount of CRB adsorbed was higher than that of the MRB in the binary system. $\mathrm{CRB}$ at $\mathrm{pH}$ of 9 was $75 \%$ compared to $50 \%$ of MRB.

A possible explanation to this observation in adsorption with change in $\mathrm{pH}$ is the point of zero charge pHpzc of the adsorbent. This is the point at which adsorbent is neutral, while beyond this the material becomes either positively or negatively charged. The $\mathrm{pHzpc}$ value for chitosan is 6.3 and below the $\mathrm{pHzpc}$ at low $\mathrm{pH}$, the concentration of the $\mathrm{H}^{+}$ions in the solution of the dye will increase, thereby resulting in the neutralization of the $\mathrm{OH}^{-}$groups on the surface of biocomposite by protonation. Therefore, the number of $\mathrm{H}^{+}$ions increases leading to an increase in the number of positively charged adsorbent sites and positively charged surface sites which is expected to probably favour the adsorption of CR (negatively charged dye) at lower $\mathrm{pH}$. Likewise, at higher $\mathrm{pH}>6.3$, it is expected that the number of $\mathrm{H}^{+}$ions will decrease leading to an increase in the number of negatively charged adsorbent sites and negatively charged surface sites which is expected to probably favour the adsorption of MR (positively charged dye). The result of the study of $\mathrm{pH}$ influence on the adsorption of $\mathrm{CR}$ in single system and binary system did not follow the expected trend from the understanding of point of zero charge because higher adsorption for the single and binary system was observed at $\mathrm{pH}$ of 7 and 9 respectively. A possible explanation for this is the presence of the LDPE in the composite which could have probably influenced the low adsorption site present for adsorbing $\mathrm{CR}$ at low $\mathrm{pH}$ as expected and favoured it adsorption at higher $\mathrm{pH}$. On the other hand, the result obtained for the adsorption of MR in both single and binary system follows the expected trend where we had the optimum absorption at the $\mathrm{pH}$ of 7 and 9 respectively. This result of the optimum $\mathrm{pH}$ for MR is supported by the findings of Egwuonwu [17] on determination of the effect of $\mathrm{pH}$ on MR adsorption by NBP and found the optimum at $\mathrm{pH} 6.5$ for the removal of MR by NBP. Similarly, Ashoka and Inamdar [18] reported an optimum pH of 7 for MR removal using treated sugarcane bagasse and activated carbon. Also, Renu and Sapna [19] in their work on adsorption and kinetic studies on the removal of Methyl red from aqueous solutions using low-cost adsorbent: guargum powder found the optimum adsorption of MR at $\mathrm{pH} 10$. 
Hence the optimum $\mathrm{pH}$ used for further study of CR in single and binary system in this experiment was $\mathrm{pH} 7$ and 9 respectively, and the optimum $\mathrm{pH}$ used for further study of MR for both single and binary system in this experiment was $\mathrm{pH} 9$.

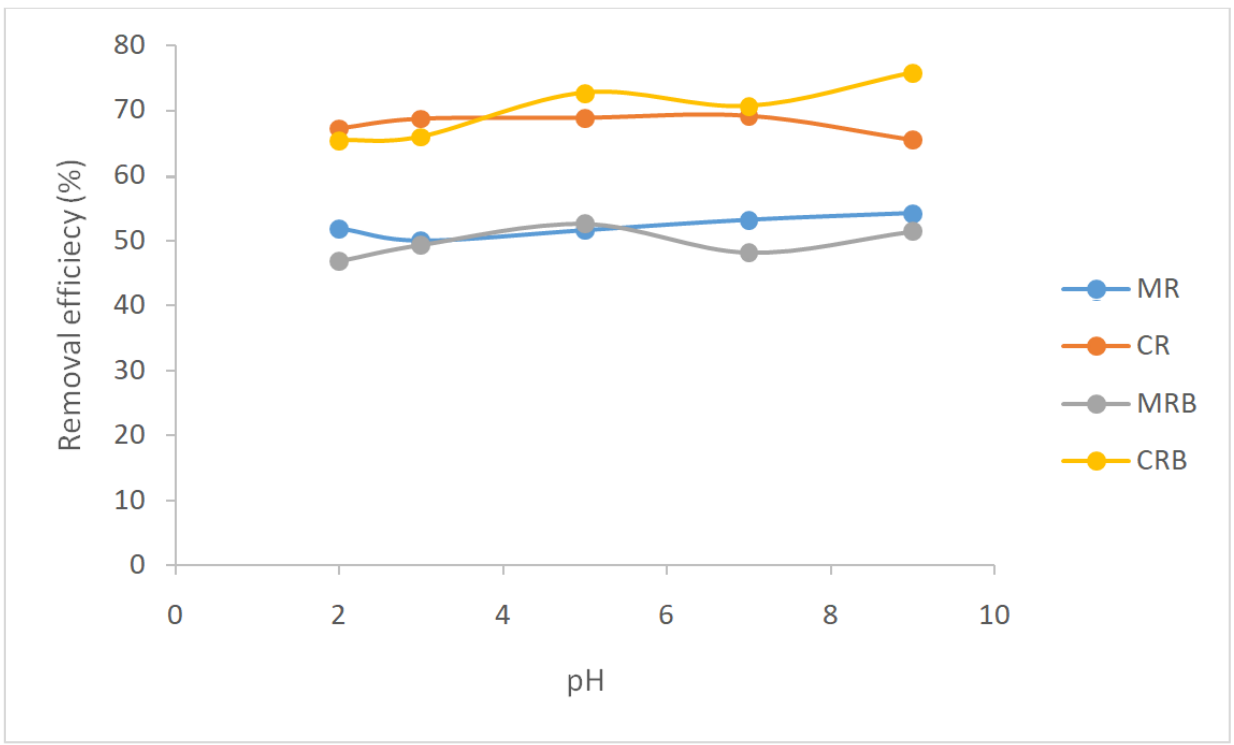

Figure 3. Effect of $\mathrm{pH}$ on adsorption of $\mathrm{MR}, \mathrm{CR}, \mathrm{MRB}$, and CRB onto LDPE/CHNP adsorbent (Adsorbent dosage of $1 \mathrm{~g}$, concentration of $50 \mathrm{ppm}$, temperature of $300 \mathrm{k}$, at $100 \mathrm{rpm}$ for 120 minutes).

\subsection{Effect of contact time on adsorption of Congo red, Methyl red and their binary system}

The effect of contact time was studied at the optimum $\mathrm{pH}$ for both dyes and $100 \mathrm{rpm}$, fixed adsorbent dose and initial dye concentration at different time intervals and shaken till equilibrium was achieved. Generally, the rate of removal of the dyes increased with an increase in contact time until equilibrium adsorption is obtained. However, from Figure 4, each of the dyes has a distinct percentage of dye removed at the equilibrium with CR having a lower percentage of $70.63 \%$ than that of MR having its maximum percentage adsorption at $96.27 \%$ in single system. In comparison with their binary system, CRB had a maximum adsorption of $56 \%$ while MRB was observed to have maximum percentage adsorption of $83 \%$ at equilibrium contact time and the adsorption were lesser than that obtained at the single system. At the equilibrium point for the dyes in both single and binary system, there was no increase in the adsorption of the dyes 
probably due to deposition of dyes on the available adsorption site of the adsorbent (Ansari and Mosayebzadeh [20]). The amount of dye desorbing at this point is in a state of dynamic equilibrium with the dye that is being adsorbed to the adsorbent. Furthermore, for $\mathrm{CR}$ adsorption, the equilibrium point was achieved at 70 minutes and 60 minutes in the single and binary system respectively. MR having its equilibrium adsorption in the single and binary system at 90 and 60 minutes respectively.

Moreover, similar observation was seen in the behavior of both dyes as their equilibrium contact time reduced in their binary system as compared to the single system. Thus, this could probably indicate that the reaction was more spontaneous even though there was reduction in the percentage adsorbed in the binary system which means the available site on the adsorbent was used faster or was not sufficiently used up in the binary system as compared to the single system.

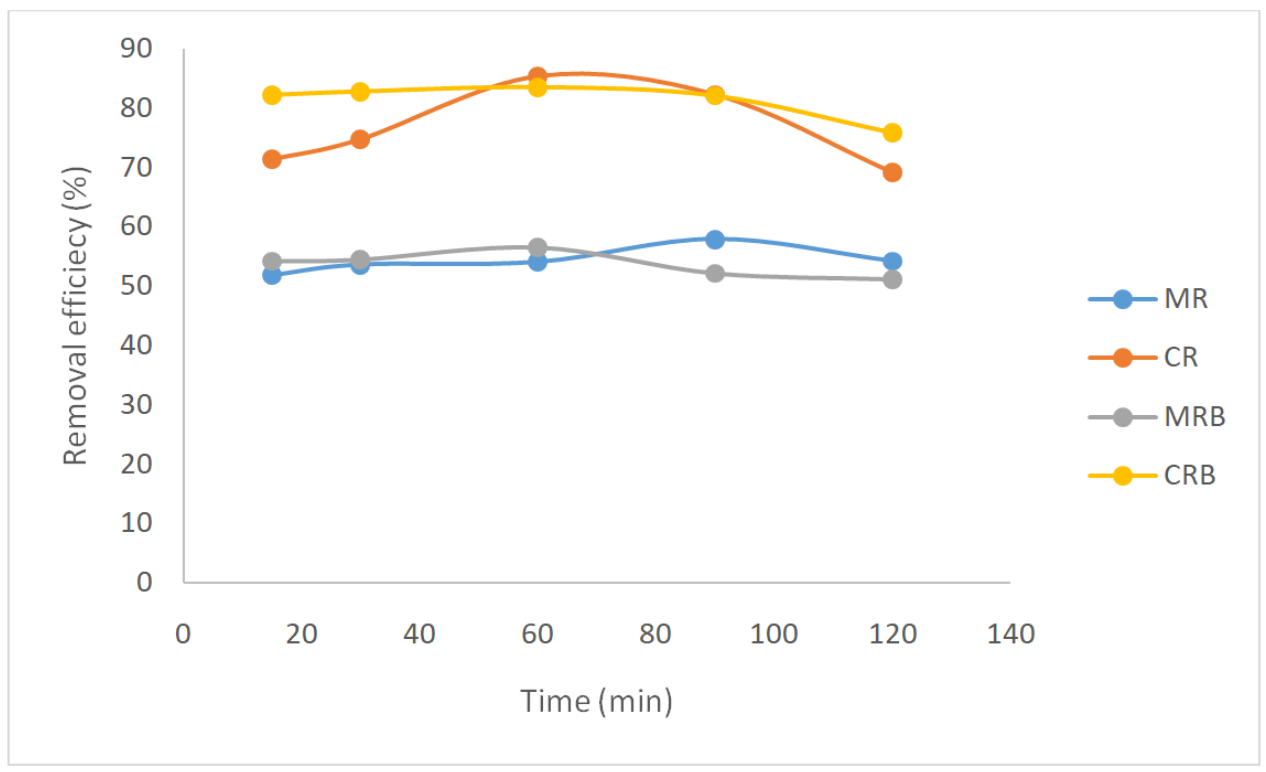

Figure 4. Effect of contact time on adsorption of $\mathrm{MR}, \mathrm{CR}, \mathrm{MRB}, \mathrm{CRB}$ onto LDPE/CHNP adsorbent (Adsorbent dosage of $1 \mathrm{~g}$, concentration of $50 \mathrm{ppm}$, temperature of $300 \mathrm{k}$, agitation speed of $100 \mathrm{RPM})$.

\subsection{Thermodynamics study on adsorption of CR, MR, CRB and MRB}

A study of the temperature dependence of adsorption reactions gives valuable knowledge about the enthalpy and entropy changes during adsorption (Auta and Hameed 
[21]). Temperature is an indicator for the adsorption nature whether it is an exothermic or endothermic process (Wongwailikhit and Horwongsakul [22]). The thermodynamic parameters $(\Delta G, \Delta H$ and $\Delta S)$ of the adsorption of $\mathrm{CR}, \mathrm{MR}, \mathrm{CRB}$ and MRB were determined.

The values of $\Delta S$ and $\Delta H$ were calculated from the slope and intercept of the Van't hoff plots listed in (Table 1). The negative values observed for the free energy, $\Delta G$, is indicative of the feasibility of the adsorption process as well as its spontaneity (Table 1). Moreover, $\Delta H$ beingnegative also indicate that it is an exothermic reaction. While the positive value of $\Delta S$ suggests the randomness of the reaction increases as the process progresses. Similarly Tapas and Naba [23] in their work on biosorption of Congo red using burned root of Eichhorniacrassipes biomass had $\Delta G$ and $\Delta H$ negative but differ in the result of their $\Delta S$ which was negative and difference could be attributed to the nature of adsorbent used.

Table 1. Table of the thermodynamic parameters of adsorption of MR, CR, MRB, CRB onto LDPE/CHNP adsorbent

\begin{tabular}{|c|c|c|c|c|}
\hline $\begin{array}{l}\text { Thermodynamic } \\
\text { parameters } \\
\Delta G\left(\mathrm{kJmol}^{-1}\right)\end{array}$ & CR & CRB & MR & MRB \\
\hline $298 k$ & -8.6709 & -7.6287 & -5.7917 & -6.4925 \\
\hline $303 k$ & -9.1608 & -8.105 .94 & -6.0366 & -6.7517 \\
\hline $308 k$ & -9.5056 & -9.214 .08 & -6.1984 & -7.0243 \\
\hline 313k & -1.0535 & -9.101 .84 & -6.3635 & -7.5926 \\
\hline $318 k$ & -1.1469 & -1.0255 .1 & -6.6703 & -7.9749 \\
\hline$\Delta S\left(\mathrm{JK}^{-1} \mathrm{~mol}^{-1}\right)$ & 138.3727 & 124.9034 & 41.60281 & 75.75877 \\
\hline$\Delta H\left(\mathrm{KJmol}^{-1}\right)$ & -32.7507 & -29.6091 & -6.6016 & -16.166 .5 \\
\hline
\end{tabular}

It was observed from the findings of the study, that the $\Delta G$ of the MRB was higher than MR and CRB was higher than CR which means the adsorption of MRB \& CRB on the adsorbent was more spontaneous. This could probably be as a result of the absence of competitive adsorption on the biosorbent between the two dyes in their binary system because Methyl red is a cationic dye while Congo red is a basic dye, so they can both freely attach to different available sites on the LDPE/CHNP biosorbent. 
Hence, the thermodynamic parameters for the two dyes in single system and binary system adsorption is in agreement with literature (Tapas and Naba [23], Achmad et al. [24]). The higher spontaneity observed in the binary system for both dyes could possibly indication that their adsorption unto LDPE/CHNP biocomposite which is an exothermic process is not competitive but rather has a complimentary effect.

\subsection{Adsorption isotherm}

The most common adsorption models are the Langmuir model (corresponding to monolayer homogeneous adsorbent surface) and the Freundlich model (corresponding to heterogeneous adsorbent surface). Moreover, for this particular experimental work the isothermal results were analyzed using well known expression for Freundlich and Langmuir isotherms.

As shown in (Figure 5), the plot of $C_{e} / Q_{e}$ against $C_{e}$ corresponds with the linearized Langmuir equation. The values of the correlation coefficient $R^{2}$ for both CR and MR given as 0.9995 and 0.9954 respectively, and 0.9991 and 0.9983 in the binary system (CRB and MRB) respectively (Table 2) were close to 1 . This confirms that the adsorption of the dyes onto LDPE/CHNP adsorbent agrees with Langmuir isotherm, which could probably suggest that the adsorption is a monolayer homogeneous adsorption. The capacity of adsorption, $Q_{0}$ defined as the maximum capacity of adsorption corresponds to the complete monolayer coverage and this showed that the mass capacity of the biocomposite for CR and MR was 23.127 and 13.030 respectively as well as 14.071 and 13.669 in their binary system (CRB and MRB) respectively. The $R_{L}$ values for both dyes being less than 1 indicates that it is a favorable adsorption process.

For the linearized Freundlich adsorption, as shown in (Figure 5) in the plots of $\ln Q_{e}$ against $\ln C_{e}$. The adsorption of CR and MR onto LDPE/CHNP agrees with the model of the Freundlich isotherm under the conditions of study with the $R^{2}$ values 0.8606 and 0.9569 respectively, and 0.9479 and 0.9863 in the binary system respectively (Table 2). The $n$ values of less than 1 (Table 2) showed that the biosorption of the dyes onto the biosorbent is a chemical process (Daramola et al. [25]). The application of both Freundlich and Langmuir isotherms to the dyes suggest that the biosorbents probably exhibit heterogeneous surface conditions and monolayer adsorption. From the result on the adsorption isotherm on the dyes and their binary system, it agrees more with the Langmuir Isotherm then the Freundlich isotherm. Thus, this gives a suggestion that the adsorption of the dyes is more of chemisorption. 
Table 2. Langmuir and Freundlich isotherm

\begin{tabular}{|lllllllll|}
\hline \multicolumn{3}{c}{ Langmuir Isotherm } & \multicolumn{5}{c|}{ Freundlich Isotherm } \\
\hline Parameters & $\begin{array}{l}\boldsymbol{Q}_{\mathbf{0}} \\
(\mathbf{m g} / \mathbf{g})\end{array}$ & $\begin{array}{l}\boldsymbol{b} \\
(\mathbf{L} / \mathbf{m g})\end{array}$ & $\boldsymbol{R}_{\boldsymbol{L}}$ & $\boldsymbol{R}^{2}$ & $\begin{array}{l}\boldsymbol{K}_{\boldsymbol{F}} \\
(\mathbf{m g} / \mathbf{g})(\mathbf{m g} / \mathbf{L})\end{array}$ & $\boldsymbol{n}$ & $\boldsymbol{R}^{2}$ \\
$\mathbf{C R}$ & 23.127 & 1.159 & 0.007 & 0.9995 & 4.476 & -12.96 & 0.9586 \\
CRB & 14.071 & 0.74 & 0.017 & 0.9991 & 3.925 & -6.99 & 0.9866 \\
MR & 13.030 & 0.412 & 0.031 & 0.9954 & 4.229 & -4.908 & 0.9569 \\
MRB & 13.669 & -0.475 & 0.027 & 0.9983 & 4.197 & -5.155 & 0.9863 \\
\hline
\end{tabular}

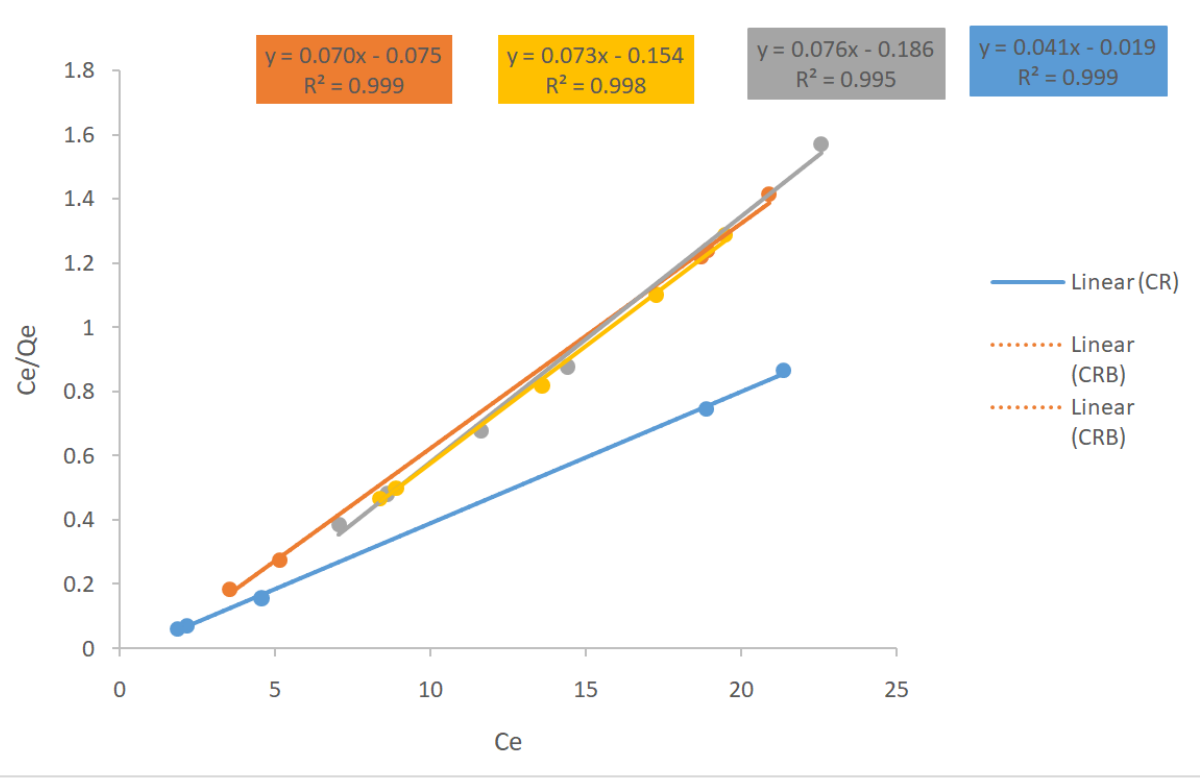

Figure 5. Langmuir isotherm for removal of $C R, C R B, M R$ and $M R B$ (Adsorbent dosage of $1 \mathrm{~g}$, temperature of $300 \mathrm{k}$, agitation speed of $100 \mathrm{RPM}$, contact time: 15, 30, 60, 90 and 120). 


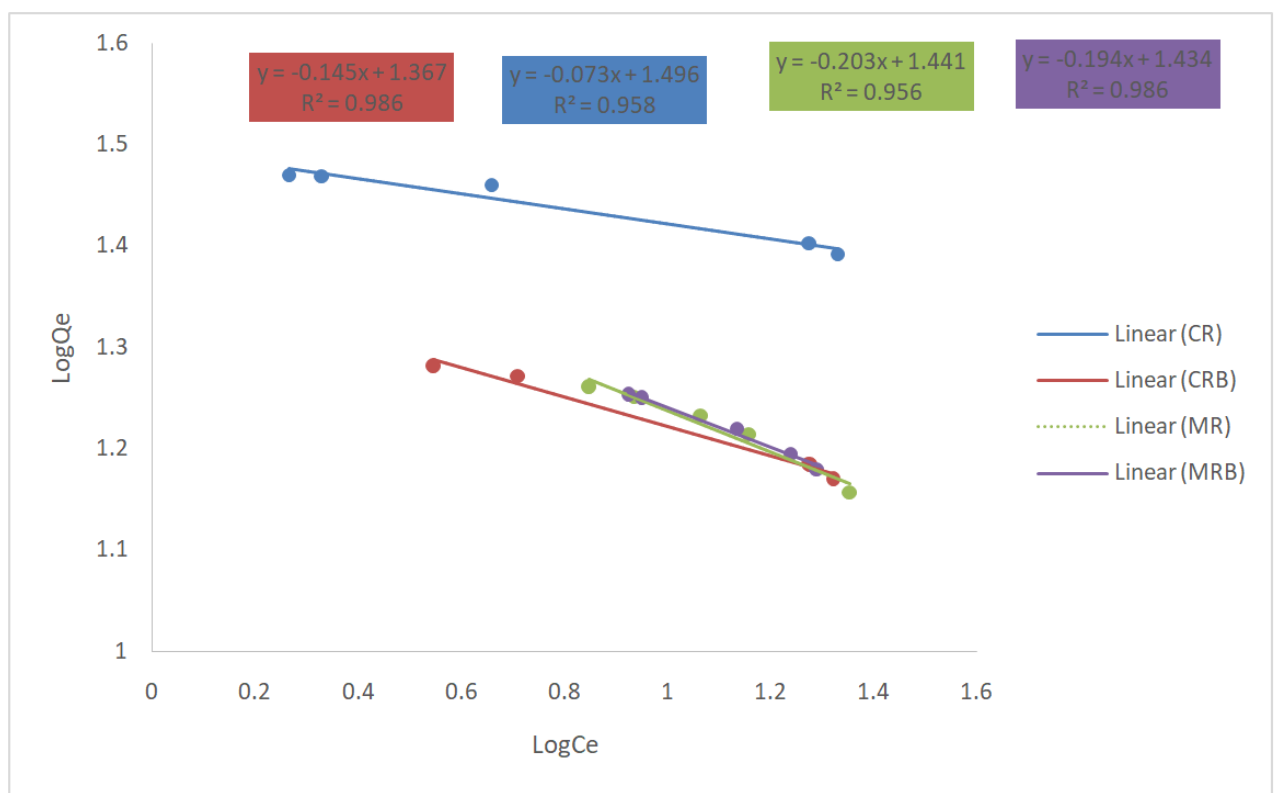

Figure 6. Langmuir isotherm for removal of CR, CRB, MR and MRB (Adsorbent dosage of $1 \mathrm{~g}$, temperature of $300 \mathrm{k}$, agitation speed of $100 \mathrm{RPM}$, contact time: 15, 30, 60, 90 and 120).

\subsection{Adsorption kinetics}

\subsubsection{Pseudo first-order kinetics}

The most popular kinetic models are the Lagergren pseudo first-order, Lagergren pseudo-second-order and the intra particle diffusion models. From the experiment, it was observed that the pseudo-first-order model did not fit well as $R^{2}<0.99$. The calculated $q_{e}$ values do not agree with the experimental $q_{e}$ values which further suggest that adsorption of all the two dyes and their binary system adsorbed onto LDPE/CHNP do not follow first-order kinetics. The result of this study is supported by the findings of Ashoka and Inamdar [18] in their research on the adsorption removal of methyl red from aqueous solutions with treated sugar cane bagasse and activated carbon. 


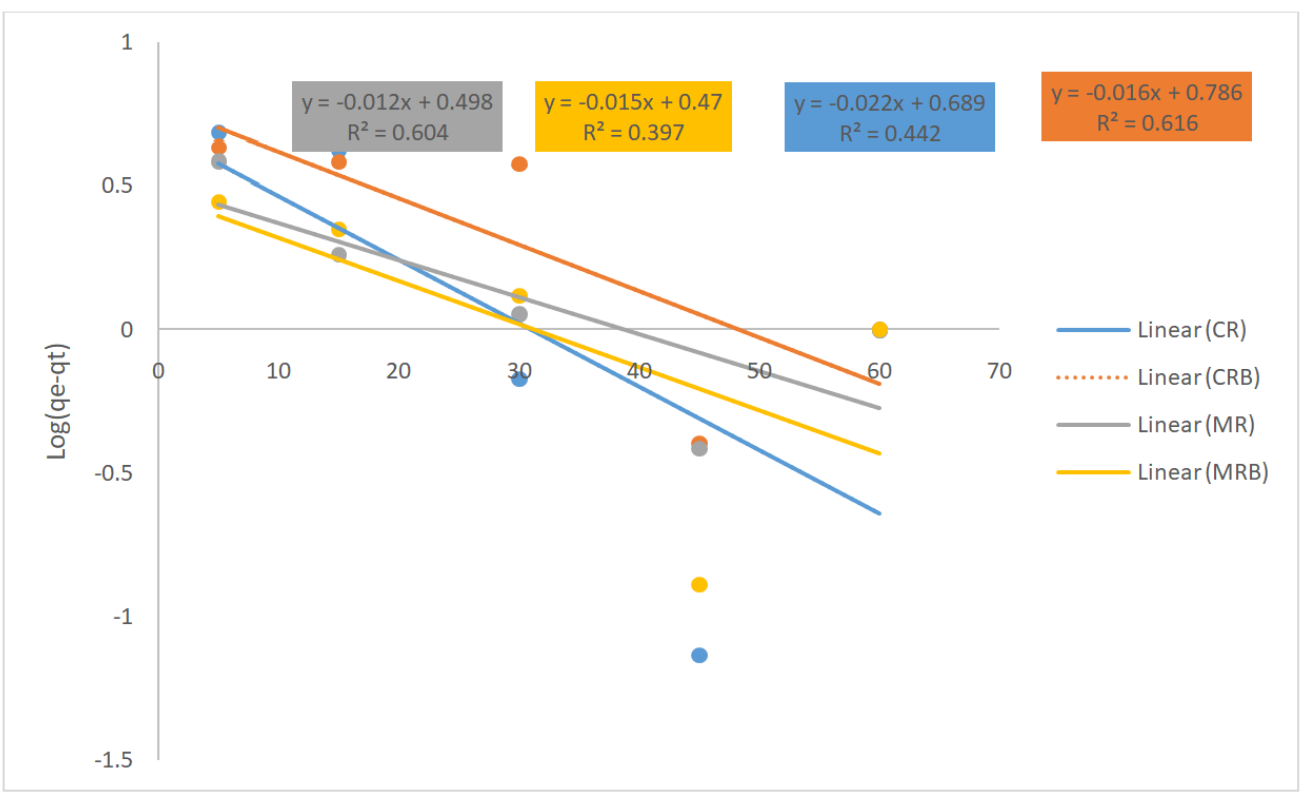

Figure 7. Pseudo first order kinetics for the removal of $C R, C R B, M R$ and $M R B$ (Adsorbent dosage of $1 \mathrm{~g}$, temperature of $300 \mathrm{k}$, agitation speed of $100 \mathrm{RPM}$, contact time: 15, 30, 60, 90 and 120).

\subsubsection{Pseudo second-order kinetics}

Kinetic modelling of $\mathrm{CR}$ and MR adsorption onto LDPE/CHNP followed a Lagergren pseudo-second-order model (Figure 8), which is predicated on the assumption that the rate limiting step may be chemisorption, i.e., involving valency forces by exchange or sharing of electrons with the $\mathrm{N}$ atom of the adsorbent. The equilibrium capacity, $q_{e}$, for the dyes were calculated with CR having the highest value 30.486 and 20.080 in the binary system (CRB) compared to the 18.718 of MR and 18.429 of MRB. The result of the findings of Ashoka and Inamdar [18] as well as Renu and Sapna [19] in the adsorption of MR onto adsorbent did not follow pseudo first order but agreed with the pseudo second-order kinetics.

The second order kinetics are regarded as the two-site or bi-continuum models, where two reactions are assumed to take place either in parallel or series. One of the reaction is said to be rapid while the other is slower to reaches equilibrium, which could proceed for a long period of time (Yeşim and Başak [1]). The calculated and experimental values of $q_{e}$ are in good agreement for the Pseudo-second-order model with correlation coefficient 
$R_{2}>0.99$. Therefore, this suggest that the Pseudo-second-order model better represented the adsorption kinetics as compared to Pseudo first order model for adsorption of CR, MR and their binary system (CRB and MRB) onto the LDPE/CHNP biosorbent shown below in (Figure 8). Even though competition for available site is not expected to occur between the two dyes of different ions, but the reduction in the $q_{e}$ values for both dyes in the binary system can be attributed to the possibilities of competition for the available site on adsorbent (Yeşim and Başak [1]).

Table 3. Kinetics study on the adsorption of Congo red, Methyl red and their binary system

\begin{tabular}{|c|c|c|c|c|c|c|}
\hline & \multicolumn{2}{|c|}{ Pseudo First Order } & \multicolumn{2}{|c|}{ Pseudo Second Order } & \multirow[b]{2}{*}{$\begin{array}{l}h \\
(\mathrm{mg} / \mathrm{g}) / \mathrm{min}\end{array}$} & \multirow[b]{2}{*}{$R^{2}$} \\
\hline & $K_{1}$ & $R^{2}$ & $K_{2}$ & $\begin{array}{l}q_{e} \\
(\mathrm{mg} / \mathrm{g})\end{array}$ & & \\
\hline CR & 0.051647 & 0.4603 & 0.016667 & 30.486 & 15.490 & 0.9996 \\
\hline CRB & 0.038121 & 0.6169 & 0.017638 & 19.9262 & 7.003 & 0.9984 \\
\hline MR & 0.02967 & 0.6041 & 0.02611 & 18.718 & 9.148 & 0.9994 \\
\hline MRB & 0.03468 & 0.3976 & 0.026079 & 18.429 & 8.857 & 0.9983 \\
\hline
\end{tabular}

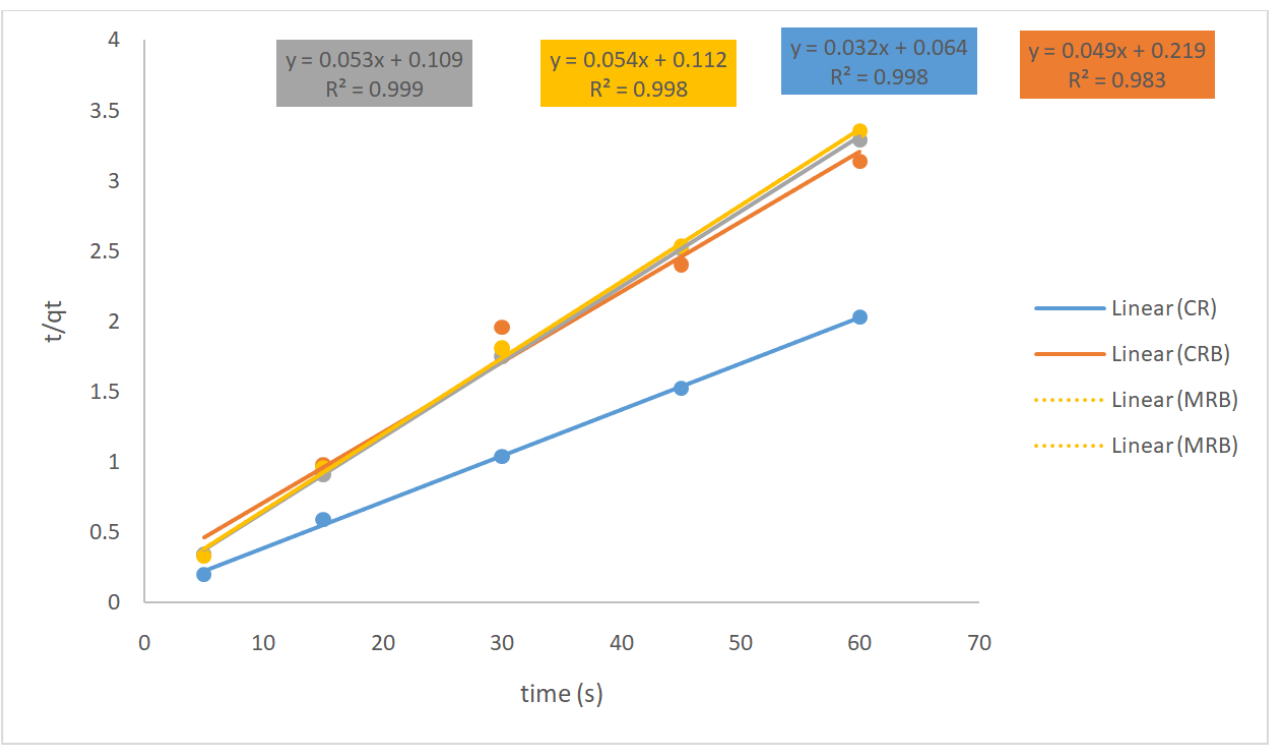

Figure 8. Pseudo second order kinetics for the removal of $C R, C R B, M R$ and MRB(Adsorbent dosage of $1 \mathrm{~g}$, temperature of $300 \mathrm{k}$, agitation speed of $100 \mathrm{RPM}$, contact time: 15, 30, 60, 90 and 120). 
The presence of Chitosan in the LDPE/CHNP biocomposite with active sites is strongly responsible for the biocomposite interaction with the dyes which made it possible for adsorption to take place. The adsorption mechanisms for dye molecules onto chitosan occurs with surface adsorption, diffusion, chemisorption and adsorptioncomplexation. From literature, adsorption-complexation is the prevalent theory for adsorption mechanisms for dye molecules onto chitosan. Different kinds of interactions like chemical bonding, ion-exchange, hydrophobic attractions, hydrogen bonds, physical adsorption, van der Waals force, aggregation mechanisms, dye-dye interactions, etc., can act simultaneously (Gerente et al. [26], Srinivasan and Viraraghavan [6]). Chemisorption (ion-exchange, electrostatic attractions) is the most prevalent mechanism with the $\mathrm{pH}$ as the main factor affecting adsorption. Chemisorption is a strong type of adsorption in which molecules are not exchanged but electrons may be exchanged. Chemisorption is especially cited as the main mechanism for the adsorption of anionic dyes in acidic conditions (Yeşim and Başak [1]).

The adsorption mechanism of anionic dyes by chitosan is described by the following mechanism: in the presence of $\mathrm{H}^{+}$, the amino groups of chitosan become protonated; also, in aqueous solution, the anionic dye is first dissolved and the sulfonate groups in the case of acid or reactive dyes dissociate and are converted to anionic dye ions; the adsorption process then proceeds due to the electrostatic attraction between these two counter ions (Goze [27]). For the cationic dye (Methyl red), the adsorption capacity was generally recorded to be low in comparison to acidic dyes (Congo red). This was due to the positive charge of dye that creates strong coulombic repulsions between chitosan and dye (Gerente et al. [26]). However, the hydroxyl group (-OH) in chitosan could adsorb the basic dye via covalent and hydrogen bonding. The interaction of Methyl red with chitosan occurs mainly by van der Waals forces and hydrogen bonding (Kyzas and Lazaridis [28]).

Competitive adsorption occurs where the adsorption of a mixture of adsorbates is carried out on just a surface. Some of the components in the effluent may induce the adsorption of others or may co-adsorb along with another components. However, only very limited information is available on the competitive adsorption of cationic dye molecules with chitosan-based materials. Those having the greatest ionic potential would be removed first, and if the sites were still undersaturated, then those having lower ionic potential would be removed in sequence. This underlining fact probably explains why 
more of the anionic dye (Congo red) was adsorbed in the binary system compared to the cationic (Methyl red) dye even when there is no competitive adsorption between them but we rather have more electronegative molecules attracted to the surface of chitosan more strongly. According to Yeşim and Başak [1], the presence of more than one dye or component such as metal ions in a solution creates competition for adsorption sites, and thereby leading to increase in the total adsorption capacity of the adsorbent.

Although in this study, the presence of Congo red and Methyl red in the solution did not bring about competition for adsorption site. The chelation between cations and chitosan chains, which decreased the electrostatic interaction between Methyl red and chitosan could also be responsible for the reason it gave lower adsorption capacity compared to Congo red. Both components, Congo red and Methyl red dye have different ionic properties, so that their dual adsorption systems LDPE/CHNP are not competitive. They are able to attach freely with different active sites present in the adsorbent which could be responsible to the closeness in their adsorption efficiency in the binary system.

\section{Conclusion}

The LDPE/CHNP biocomposite was applied as a biosorbent for the adsorption of MR and CR in both single and binary system. The result of the thermodynamic study of the adsorption process revealed that it was an exothermic reaction, with negative value of $\Delta G$ indicating that the reaction was feasible. The adsorption equilibrium study was tested with both Langmuir and Freundlich isotherm and the result showed they agree more with Langmuir which implies that they were more of chemisorption than physiosorption reaction. The kinetics study was also done with pseudo first order and pseudo second order kinetics, and the result revealed that they were pseudo second order reaction. The adsorption of both dyes in binary was not competitive since the two dyes were of opposite charges and were able to attach freely with different active sites present in the adsorbent was responsible for the closeness in the adsorption efficiency of both dyes in the binary system.

The LDPE/CHNP biocomposite has proved to be an efficient adsorbent for CR (anionic dye) and MR (cationic dye) in single and two-component system which are frequently encountered composition of industrial effluents, so it could be applied as an alternative source of industrial waste water treatment. 


\section{References}

[1] S.A. Yeşim and G. Başak, Removal of Methyl Red, a cationic dye, Acid Blue 113, an anionic dye, from wastewaters using chitin and chitosan: influence of copper ions, Desalination and Water Treatment 73 (2017), 289-300.

https://doi.org/10.5004/dwt.2017.20408

[2] L. Zhang, Y. Zeng and Z. Cheng, Removal of heavy metal ions using chitosan and modified chitosan: A review, Journal of Molecular Liquids 214 (2016), 175-191. https://doi.org/10.1016/j.molliq.2015.12.013

[3] V.K. Gupta, P.J.M. Carrott, M.M.L.R. Carrott and Suhas, Low-cost adsorbents: Growing approach to wastewater treatment, a review, Crit. Rev. Env. Sci. Tech. 39 (2009), 783842. https://doi.org/10.1080/10643380801977610

[4] V.K. Gupta and Suhas, Application of low-cost adsorbents for dye removal - A review, J. Environ. Manag. 90 (2009), 2313-2342.

https://doi.org/10.1016/j.jenvman.2008.11.017

[5] I. Michalak, K. Chojnacka and A. Witek-Krowiak, State of the art for the biosorption process - A review, Application of Biochemistry and Biotechnology 170 (2013), 13891416. https://doi.org/10.1007/s12010-013-0269-0

[6] A. Srinivasan and T. Viraraghavan, Decolorization of dye wastewaters by biosorbents: A review, J. Environ. Manag. 91 (2010), 1915-1929.

https://doi.org/10.1016/j.jenvman.2010.05.003

[7] J. Wang and S. Zhuang, Removal of various pollutants from water and wastewater by modified chitosan adsorbents, Critical Reviews in Environmental Science and Technology 47(23) (2017), 2331-2386.

https//doi:10.1080/10643389.2017.1421845

[8] Y.C. Wong, Y.S. Szeto, W.H. Cheung and G. McKay, Effect of temperature, particle size and percentage deacetylation on the adsorption of acid dyes on chitosan, Adsorption 14 (2008), 11-20. https://doi.org/10.1007/s10450-007-9041-5

[9] G.Z. Kyzas and D.N. Bikiaris, Recent modifications of chitosan for adsorption applications: A critical and systematic review, Marine Drugs 13 (2015), 312-337. https://doi.org/10.3390/md13010312

[10] I. Langmuir, The constitution and fundamental properties of solids and liquids, J. Am. Chem. Soc. 38 (1916), 2221-2295. https://doi.org/10.1021/ja02268a002

[11] H.M.F. Freundlich, Uber die Adsorption in Losungen, Zeitschrift für Physikalische Chemie 57A (1906), 385-470. 
[12] Y.S. Ho and G. McKay, Kinetic models for the sorption of dye from aqueous solution by wood, Process Safety and Environmental Protection 76 (1998), 183-191. https://doi.org/10.1205/095758298529326

[13] A. Megha, K.A. Mukesh, S. Nalini, P. Sarika, D. Ritu and G. Priyanka, Preparation of chitosan nanoparticles and their in-vitro characterization, Int. J. Life Sci. Scienti. Res. 4(2) (2018), 1713-1720. https// doi:10.21276/ijlssr.2018.4.2.17

[14] M.B. Bolanle, O.B. Adegoke, O.A. Cecilia, S.A. Olushola, F.A. Sunday and O.O. Ekemena, Adsorption and desorption studies of Delonix regia pods and leaves: Removal and recovery of $\mathrm{Ni}(\mathrm{II})$ and $\mathrm{Cu}(\mathrm{II})$ ions from aqueous solution, Drink. Water Eng. Sci. 13 (2020), 15-27. https://doi.org/10.5194/dwes-13-15-2020

[15] G. Saraswathy, S. Pal, C. Rose and T.P. Sastry, A novel bio-inorganic bone implant containing deglued bone, chitosan and gelatin, Bull. Mater. Sci. 24 (2001), 415-420. https://doi.org/10.1007/BF02708641

[16] M. Sunilkumar, T. Francis, E.T. Thachil and A. Sujith, Low density polyethylenechitosan composites: A study based on biodegradation, Chemical Engineering Journal 204-206 (2012), 114-124. https://doi.org/10.1016/j.cej.2012.07.058

[17] Dim P. Egwuonwu, Adsorption of methyl red and methyl orange using different tree bark powder, Academic Research International 4 (2013), 330-338.

[18] H.S. Ashoka and S.S. Inamdar, Adsorption removal of methyl red from aqueous solution with treated sugar cane bagasse and activated carbon - a comparative study, Global Journal of Environmental Research 4 (2010), 175-182.

[19] S. Renu and S. Sapna, Adsorption and kinetic studies on the removal of methyl red from aqueous solutions using low-cost adsorbent: guargum powder, International Journal of Scientific and Engineering Research 7(3) (2016), 675.

[20] Ansari and Mosayebzadeh, Investigation of a basic dye removal from aqueous solution onto chemically modified Unye bentonite, J. Mater. Process Technol. 191 (2011), 235237.

[21] M. Auta and B.H. Hameed, Optimized waste tea activated carbon for adsorption of Methylene Blue and Acid Blue 29 dyes using response surface methodology, Chemical Engineering Journal 175 (2011), 233-243. https://doi.org/10.1016/j.cej.2011.09.100

[22] K. Wongwailikhit and S. Horwongsakul, The preparation of iron (III) oxide nanoparticles using W/O microemulsion, Mater. Lett. 65 (2011), 2820-2822. https://doi.org/10.1016/j.matlet.2011.05.063

[23] K.R. Tapas and K.M. Naba, Biosorption of Congo Red from aqueous solution onto 
burned root of Eichhornia crassipes biomass, Appl. Water Sci. 7 (2017), 1841-1854. https://doi.org/10.1007/s13201-015-0358-z

[24] A. Achmad, J. Kassim, T.K. Suan, R.C. Amat and T.L. Seey, Equilibrium, kinetic and thermodynamic studies on the adsorption of direct dye onto a novel green adsorbent developed from Uncaria Gambir extract, J. Phys. Sci. 23 (2012), 1-13.

[25] Daramola Oluwatosin Emmanuel, Bello Lukman Abidemi and Ogunyemi Olusayo Joseph, Removal of chromium (VI) from aqueous solution using Moringa oleifera pods as biosorbent, International Journal of Current Research in Applied Chemistry and Chemical Engineering 2(1) (2018), 48-57.

[26] C. Gerente, V.K.C. Lee, P. Le Cloirec and G. McKay, Application of chitosan for the removal of metals from wastewaters by adsorption-mechanisms and models review, Crit. Rev. Env. Sci. Tec. 37 (2007), 41-127. https://doi.org/10.1080/10643380600729089

[27] B. Goze, Removal of heavy metal ions and dyes from aqueous media with the adsorption method by using micropolymeric materials, chitin and chitosan, Dissertation, Hacettepe University, 2013.

[28] G.Z. Kyzas and N.K. Lazaridis, Reactive and basic dyes removal by sorption onto chitosan derivatives, Journal of Colloid and Interference Science 331 (2009), 32-39. https://doi.org/10.1016/j.jcis.2008.11.003 